\title{
Financial Innovation and the Global Crisis
}

\author{
Manuel Sánchez \\ Deputy Governor, Banco de México \\ Mexico City, Mexico
}

This is an expanded version of a speech delivered at the Sixth China International Finance Forum, Pudong, Shanghai, on October 24, 2009. The opinions expressed herein are my own and do not necessarily reflect those of Banco de México.

\begin{abstract}
This essay focuses on the nature and prospects of financial innovation in light of the recent global economic crisis. My central point is that although financial innovation has lately fallen out of favor because some of its products acted as vehicles in the credit boom that led to the crisis, criticism should be taken with caution. Innovation has been with us for a long time, and its overall contribution to finance and welfare has been positive. Provided that we strengthen prudential regulation to discourage excessive risk taking in the future, innovation can continue to benefit our societies.
\end{abstract}

Keywords: Financial innovation, Financial Crisis

\section{Introduction}

The recent global financial crisis has highlighted the limitations and hazards of financial innovation while dimming the light on its core benefits for an economy. The main reason is that many complex financial instruments associated with innovation such as collateralized debt obligations (CDOs) and credit default swaps (CDSs) were extensively used as vehicles in the credit expansion that led to the crisis. In particular, mortgage securitization in the boom years did not help to reduce the informational problems that are typical of credit transactions, nor did it induce appropriate risk assessment.

Notwithstanding these facts, the contribution of innovation to the crisis deserves careful evaluation. Credit derivatives and default swaps have existed for a long time, and their availability and role in facilitating loan expansion hardly make them the root cause of a crisis. Derivatives per se do not create risk, they merely transfer it. Furthermore, innovation has had a crucial and positive role in financial modernization, leading to the improvement of economic wellbeing. Hence, provided that we strengthen prudential regulation to discourage excessive risk taking in the future, innovation can continue to benefit our societies.

The organization of this essay is as follows. Section I discusses the nature and sources of innovation, viewed as a factor inherent in human development. Section II reviews the effects of financial innovation on material wellbeing. Specifically, innovation has helped individuals and businesses to attain their economic goals more efficiently, enlarging their possibilities for mutually advantageous exchanges. As new products contribute to the deepening of financial markets, innovation, in turn, fosters economic development.

Section III explores the relationship between innovation and the recent financial crisis. The main problem behind the crisis was the housing boom and the eventual insolvency of innumerable mortgage holders. The resulting financial distress uncovered the lax standards with which securitized credit was originated and the willingness of investors to take on substantially underestimated risks. Although the debate is still ongoing, the view that there were fundamental forces independent from innovation behind the housing and credit boom is widely acknowledged.

Section IV describes Mexico's recent experience with financial innovation, which has been positive. Paradoxically, some benefits emerged directly from the deep financial crisis suffered by the country in 1995. Three areas that became more modernized are: foreign exchange (FX) transactions, the domestic debt market, and banking sector practices. Financial innovation has also emerged from other sources, as is the case of Mexico's modernized payment systems.

Section V discusses the need for prudential regulation and supervision in order to reduce the likelihood of major financial disruptions and, should they happen, the need to have efficient response mechanisms in place. Financial 
authorities should discourage practices that may lead to financial distress without inhibiting the evolution of markets and financial innovation. Two pillars of financial stability are a sound macroeconomic environment and an efficient regulatory and supervisory framework for financial institutions.

The most urgent step in the second area is to reduce to a minimum possible level the moral hazard related to the problem of banks considered to be "too-big-to-fail." New preventive measures may also include more stringent capital adequacy standards, reserve and liquidity ratios for intermediaries, contingent capital and countercyclical loan-loss provisioning, and more information disclosure. For example, standardized CDSs could be required to be registered on and possibly trade and clear with a central counterparty, which could increase the transparency and liquidity of these instruments. In the end, however, regulatory and supervisory efforts should never crowd out the responsibility and due diligence of market participants.

\section{The Nature and Sources of Innovation}

Innovation is a factor inherent in human development. Throughout history, men and women have sought new forms to respond to the challenges and opportunities presented by life's struggles. This creativity has made possible innumerable scientific revolutions. It has also enriched finance and enhanced the possibilities for economic prosperity.

Broadly speaking, financial innovation consists of any way in which finance and the financial system are modernized. This notion encompasses new or transformed financial instruments, institutions, practices, and markets. Because of their ample scope, any list of historical financial innovations can be both very long and necessarily incomplete.

One can go back far in history and find important building blocks underlying today's financial system. For example, in China in the ninth century, the world saw for the first time paper money, a bill of exchange developed by merchants, the predecessor of government-issued fiat money. Also, medieval Europe witnessed the establishment of organizations specializing in deposits and the lending of money and the creation of generally spendable IOUs, all essential functions of modern banking. More recent progress includes widely used instruments such as debit and credit cards and derivatives, services like ATMs, clearing houses, and electronic payments and processes such as credit scoring models.

This dynamic modernization has taken place because, among other factors, people have sought to satisfy new needs, address agency and other information problems, reduce transaction costs, administer risks, and exploit profit opportunities. Obviously, a specific financial innovation can pursue more than one end.

The possible sources of innovation from market participants are various, but for simplicity's sake, I will group them in two broad categories: changes in information technology and changes in the economic environment. (For alternative classifications see, for example, Mishkin and Eakins, 2009 and Tufano, 2003). The first set includes products and services based on new technological possibilities that lower the cost of acquiring and processing information and make financial transactions more efficient. Clear examples of this type of innovation are automated underwriting systems, mobile banking, and electronic trading platforms for foreign exchange, capital and derivatives products.

The second category refers to changes in market and regulatory conditions faced by economic agents. For example, the abandonment of the Bretton Woods fixed exchange-rate system and the increases in the rate and volatility of worldwide inflation in the 1970s gave rise to credit products such as adjustable rate mortgages in the United States, and deepened the use of a variety of FX and interest rate derivatives, such as futures, forwards, swaps and options, now widely used in most countries.

\section{The Effects of Innovation}

Given the above description, it should not be surprising that financial innovation has increased material wellbeing. In particular, innovation has helped individuals and businesses to attain their economic goals more efficiently, enlarging their possibilities for mutually advantageous exchanges of goods and services.

By increasing the variety of products available and facilitating intermediation, financial innovation can promote savings and channel these resources to the most productive uses. It may widen the availability of credit, help refinance obligations and allow for better allocation of risk, matching the supply of risk instruments to the demand of investors willing to bear it. In addition, innovation may encourage technological progress when the requirements for information technology generate new technological projects, and induce their funding as in the case of venture capital. (For an elaboration of this argument, see Chou and Chin, 2004). 
As a result, financial innovation may lower the cost of capital, promote greater efficiency, and facilitate the smoothing of consumption and investment decisions with considerable benefits for households and corporations. As the new products contribute to the deepening of financial markets, innovation, in turn, fosters economic development. A large body of literature shows an association between the depth of a country's financial markets and its rate of productivity growth. Furthermore, there is some empirical evidence that causation runs from the former to the latter. (For a survey, see Levine, 2005).

Two issues may limit the social benefits from innovation. One refers to the possibility that certain innovations may be designed to circumvent taxes and regulations. To the extent that these government interventions are justified by welfare considerations, the resulting contribution from innovation may be inferior from society's point of view.

Although this possibility is real, innovations are seldom the result of one objective, and those designed exclusively for the aforementioned purpose are likely more the exception than the rule. On the other hand, certain regulations that in the past were circumvented may have been inefficient, such as "Regulation Q" which capped interest rates on deposits, and branch restrictions that limited bank competition in the United States. To preclude avoidance and other unintended consequences from policy measures, the classical advice for taxes and regulations applies here: make them simple and uniform and, especially, seek to induce the "right" incentives for economic agents.

A second possible limitation is that the use given to specific innovations might increase financial instability. To be discussed in the next section, this consideration is of particular importance given the prominent role that certain innovations, notably derivatives, played in recent years. For now, I would just like to say that derivatives have long been used for risk diversification and management of uncertainty. In fact, many instruments such as interest rate swaps gained popularity during times of high market volatility, when counterparties exchanged predictable returns for expected higher benefits. The result has been less instability. (For the stabilizing role of portfolio insurance trading in the stock market crash of 1987, see Miller, 1991).

\section{The Recent Financial Crisis}

Now let me turn to the subject of the recent global crisis and the possible role of innovation. The obvious association between the two comes from the fact that the mortgage market contraction, which in many countries evolved into a recession in 2008-2009, was preceded by intensive use of certain complex financial instruments such as CDOs and CDSs in the United States and other countries.

It should be recognized that virtually any financial product holds dangers and can be improperly used. Potential problems are likely to increase with the complexity of the instruments, the insufficiency of information conveyed by sellers, and the lack of due diligence on the part of investors. The massive mortgage securitization of recent years apparently scored poorly in these areas. Mortgage securitization in the boom years did not help to reduce the informational problems that are typical of credit transactions, nor did it induce appropriate risk assessment.

To be fair, securitization of illiquid assets always poses potential benefits and perils. As risks are sold to economic agents who have additional capacity to bear them, risk allocation may improve. Banks can reinvest freed-up resources in the economy, increasing the liquidity of credit markets. However, built-in separation between the loan originator and the investor may make information more asymmetric. Also, credit risk transfer can lead to a reduction in efforts on the part of banks to control credit quality and mitigate default risks, while holding a diversified portfolio and buying CDSs may discourage investors from monitoring loans.

However, credit derivatives and default swaps have existed for a long time, and their availability and their role in facilitating loan expansion hardly make them the root cause of a crisis. Derivatives per se do not create risk, they merely transfer it. Systemic crises occur when investment booms and rapid credit expansions collapse because the expectations about high future returns that drove them are not fulfilled. In the recent crisis, the main problem was the housing boom and the eventual insolvency of innumerable mortgage holders. The resulting financial distress uncovered the loose standards with which securitized credit was originated and the willingness of funds and institutions managed by competent people to take on substantially underestimated risks.

Although the debate is still ongoing, the view that there were fundamental forces independent from innovation behind the housing and credit boom is widely acknowledged. For example, former Federal Reserve Board Chairman Alan Greenspan has singled out an excess of global intended savings relative to investment as explaining the unusually low long-term interest rates in the world that led to speculation in the housing markets. Others have argued that the crisis was to a large extent a consequence of public policy decisions in the United States and other countries. These include an expansionary monetary policy that sought to fight potential deflation during 2002-2005, the government's promotion of "affordable housing" and high mortgage leverage, the delegation of measures of bank risk to internal models and rating agencies and, perhaps, the implicit guarantee that 
the government would bail out any big troubled financial institution. (See Greenspan, 2009 and for a different view see Taylor, 2009).

In any case, it is striking that supervisors did not implement measures to correct the generalized underestimation of risks. The use of financial instruments reflected the incentives faced by economic agents. As interest rates remained low for an extended period of time, the appetite for riskier, more profitable instruments increased. Securitization and CDSs were the means that provided the market with the returns it was expecting. It is now evident that the risk and return evaluation of securities on the part of the rating agencies made the problems of asymmetric information and moral hazard more severe.

\section{The Mexican Experience}

In recent years, Mexico's experience from financial innovation has been positive. Paradoxically, some of the benefits associated with innovation emerged because of the deep financial crisis suffered by the country in 1995 . At least three fields of modernization point in this direction.

The first change took place in the FX market. Given the depletion of the central bank's international reserves by the end of 1994, Mexico adopted a flexible exchange rate regime, which has been maintained since then due to its efficiency in allowing the economy to adjust to external shocks, among other things. To deepen the FX market in the aftermath of the crisis, the Bank of Mexico liberalized its regulation on forward and futures transactions. The resulting development of this market uncovered, for the first time, implicit interest rates in peso debt for different maturities.

Hence, a second related area of innovation took place in the domestic debt market. During 1997-2006 the government complemented the forward interest rates implicit in FX transactions by issuing debt for gradually longer terms, up to 30 years. For the creation of the yield curve, two developments were crucial. On the one hand, the stabilization process that lowered the inflation rate from $51 \%$ in 1995 to approximately $4 \%$ since 2003 provided a predictable macroeconomic environment. On the other, the 1995 private pension reform substituted the old defined benefit pay-as-you-go system with a fully funded defined contribution system based on individual accounts. The new pension funds, managed by private administrators, were required to hold a high proportion of their investments in risk-free debt, which converted them into the main buyers of long-term government bonds.

Also, the completed term structure of interest rates permitted the development of the repo and securities lending market as well as the formation of the swap market for the interbank interest rate ("TIIE") at several maturities. This evolution deepened the liquidity of the money market, which facilitated pricing and further enhanced the hedging instruments that emerged. The TIIE at different maturities is now a typical reference in the pricing of corporate debt issues.

A third field of innovation has been an improvement in banking sector practices. In order to confront the insolvency of banks in the wake of the 1995 crisis and prevent future problems, the country eliminated prior restrictions on foreign ownership and upgraded the regulation and supervision of financial institutions. The resulting high-capitalization and loan-loss reserve ratios, as well as more adequate lending procedures, made banks relatively resilient to the financial turbulence and recession in 2008-2009.

One lending practice deserves special mention. Before 1995, several banks used to offer mortgage products characterized by adjustable interest rates, which often translated into negative amortization for the first years of the loans. These credits proved to be extremely vulnerable to the highly inflationary environment that prevailed once the 1995 crisis erupted. The deterioration of the mortgage portfolio was very rapid, substantially worsening the financial situation of the credit institutions. As a consequence of this traumatic experience, banks in Mexico no longer offer loan products that have negative amortization schemes. Instead, most intermediaries offer fixed-interest-rate mortgages for longer maturities, while at the same time they are able to transform the duration risk in the swap market.

Finally, financial innovation has also emerged from sources different from the 1995 crisis. A clear example is the modernization of the payment systems. While a rising proportion of the continuously growing number of payments in the economy is conducted outside bank branches, notably through alternative delivery channels such as phone and internet banking, this transformation has favored the most efficient means. In particular, transactions through electronic transfers and point-of-sale terminals have been gaining importance relative to those based on checks or ATMs.

Behind the modernization of the payment systems, there have been two major innovations. One has been the merger of the high-value and low-value payment systems onto the same real-time platform. This unified structure, managed by the Bank of Mexico, provides centralized clearing services for all payments, including transactions by 
individuals and corporations and sources as diverse as the FX, stock market, and money market exchanges. The other innovation has been the consolidation of custodian services for all types of securities issued either by the government or the private sector in a central securities depositary. These two innovations have resulted in cost efficiencies and transaction reliability and have successfully passed the stress tests of high market volatility episodes.

\section{The Need for Prudential Regulation and Supervision}

The recent global crisis has made clear the need to establish conditions that may reduce the likelihood of major financial disruptions and, should they happen, the need to have in place efficient response mechanisms. Financial authorities face the challenge of discouraging practices that may lead to financial distress without inhibiting the evolution of markets and financial innovation.

The most important conditions are those needed to abate possible causes of excessive leverage and risk taking. Hence, a first pillar of financial stability is a sound macroeconomic environment. Monetary policy should pursue its objectives, notably price stability, avoiding expansionary stances that may create undue credit or asset price booms. Similarly, fiscal and financial policy should make the long-term sustainability of financial institutions a priority, without resorting to subsidies or quantitative targets for loan origination that may lead to imprudent risk taking.

A second pillar of stability is an efficient regulatory and supervisory framework for financial institutions. Regulation should focus on making the financial system resilient to crises. For this purpose, simple and uniform rules extending to bank and nonbank financial institutions should be preferred, because they are more difficult to circumvent. Their aim should be to align incentives toward responsible risk taking and mitigate agency and moral-hazard risks.

The most urgent step is to reduce, to a minimum possible level, the moral hazard related to the "too-big-to-fail" policy. This implies clear rules for the lender-of-last-resort role of central banks, perhaps in the tradition of Bagehot. The dictum of Bagehot (1873) can be summarized as "to avert panic, central banks should lend early and freely to solvent institutions against good collateral at high rates." Furthermore, expedient resolution mechanisms seem necessary to allow an orderly winding down of big insolvent financial institutions, imposing losses on shareholders and creditors while preserving the normal functioning of the system. Contingent plans, known as "living wills," may be drawn up by specific firms to predetermine the actions leading to their own demise (Rajan, 2009). Additionally, the following key regulatory requirements may be set proportionally to the size of financial institutions.

In particular, the capital adequacy, reserve and liquidity ratios for intermediaries can be set sufficiently high to promote sound underwriting and to function as buffers in case of distress. To induce the right incentives, higher ratios of capital to risk-weighted assets could be defined exclusively in terms of equity. Additional contingent capital may be mandated in the form of subordinated debt with forced conversion into equity shares under predetermined risky conditions. The short-run service of these bonds would play a disciplinary role, and their prices could provide information about the riskiness of the specific institutions (Flannery, 2005). On the other hand, risk-weights could be set proportionally to the risk reflected in the interest rates charged by the originator, as well as to the originator's size. (For an application of this approach, see Calomiris and Powell, 2001). Additionally, loan-loss provisions could follow a countercyclical norm, similar to the "dynamic reserve provisioning" successfully implemented in Spain.

Measures to enhance information disclosure may be designed so that economic agents clearly recognize the risks they are taking. Regulatory improvements in this area appear especially promising for innovation. For example, standardized CDSs could be required to register and possibly trade and clear with a central counterparty, which could increase the transparency and liquidity of these instruments.

These measures have the advantage of being rule based and hence they do not depend on the decisions of supervisors, whose incentives at times may not address the need to prioritize and then take preemptive decisions. However, as any regulation is necessarily incomplete and rules must be enforced, supervision should play a crucial role. Also, surveillance is essential to monitor large and increasing exposures, assess potential systemic risks, and analyze possible spillover effects, among other objectives.

Finally, it should be borne in mind that regulation is not a guarantee for protection. Rather, regulation should make customers and risk managers more demanding, as it does not eradicate the risk inherent in financial products. Regulatory and supervisory efforts should never crowd out the responsibility and due diligence of market participants. 


\section{Conclusions}

Financial innovation is the natural result of human creativity and has favored households, corporations, and the economy. As new products contribute to the deepening of financial markets, financial innovation has fostered economic development. Mexico has had a constructive experience with innovation, much of which has been, paradoxically, a positive consequence of the 1995 crisis.

The recent world financial crisis unmasked fundamental forces beyond innovation that led to an extensive underestimation of risk. To reduce the likelihood of future major financial instability, regulation and supervision should help align the incentives of market participants towards prudent risk taking. However, regulation should not forestall innovation, nor should it be interpreted as a substitute for private responsibility. Rather, regulation should ensure that innovations are sufficiently transparent and understandable for markets to work efficiently and society to continue to benefit from an unceasing modernization of finance and the financial system.

\section{References}

Bagehot, Walter. (1873). Lombard Street: A Description of the Money Market. Henry S. King, Third Edition.

Calomiris, Charles W., and Andrew Powell. (2001). "Can Emerging Market Bank Regulators Establish Credible Discipline? The Case of Argentina, 1992-99" in Frederic S. Mishkin, (ed.), Prudential Supervision: What Works and What Doesn't. University of Chicago Press.

Chou, Yuan K., and Martin S. Chin. (2004). Financial Innovations and Technological Innovations as Twin Engines of Economic Growth. Mimeo, University of Melbourne, January.

Flannery, Mark. (2005). "No Pain, No Gain? Effecting Market Discipline via Reverse Convertible Debentures" in Hal S. Scott (ed.), Capital Adequacy beyond Basel: Banking, Securities and Insurance, Chapter 5, Oxford University Press.

Frederic S. Mishkin and Stanley G. Eakins. (2009). Financial Markets and Institutions, Pearson, Sixth Edition. Greenspan, Alan. (2009). The Fed Didn't Cause the Housing Bubble. Wall Street Journal, March 11.

Miller, Merton H. (1991). Financial Innovation and Market Volatility. Blackwell Publishing.

Rajan, Raghuram. (2009). "Too Systemic to Fail: Consequences and Potential Remedies," presented at the Proceedings of a Conference on Bank Structure and Competition, Federal Reserve Bank of Chicago, May.

Ross, Levine. (2005). "Finance and Growth: Theory and Evidence" in Philippe Aghion and Steven N. Durlauf, (eds.), Handbook of Economic Growth, Vol 1A, Chapter 12, Elsevier North-Holland.

Taylor, John B. (2009). Getting off Track. Hoover Institution Press.

Tufano, Peter. (2009). "Financial Innovation" in George Constantinides, Milton Harris and Rene Stulz, (eds.), Handbook of the Economics of Finance Vol 1A, Chapter 6, Elsevier North-Holland. 